\title{
La Fiebre Amarilla en Yucatán durante las épocas precolombina y colonial.
}

\author{
Historia de la Medicina
}

Renán A. Góngora-Biachi.

Laboratorio de Hematología, Centro de Investigaciones Regionales “Dr. Hideyo Noguchi”, Universidad Autónoma de Yucatán, Mérida, Yucatán, México.

\section{RESUMEN.}

La fiebre amarilla es un síndrome de fiebre hemorrágica ocasionada por un flavivirus, el virus de la fiebre amarilla, y que es transmitido por los mosquitos Aedes aegypti y Haemagogus. El virus de la fiebre amarilla ha causado epidemias importantes en el continente americano, Africa y Europa. El Popol-Vuh, libro sagrado de los mayas quichés, relata que la fiebre amarilla entre los mayas se debe a la constante convivencia con los monos y relata la epidemia de una enfermedad llamada "xekik" (vómito de sangre) ocurrida entre los años de 1480 a 1485. Otros textos sagrados como el Chilam Balam de Chumayel, Tizimín y Kaua también describen las epidemias de "xekik". Fray Diego de Landa, en su obra Relación de las Cosas de Yucatán, escrita en 1560, refiere que la primera epidemia en la región ocurrió aproximadamente en 1483-84. Descrita como la "peste", hubo epidemias de fiebre amarilla en 1569, y 1571-
1572. El impacto de estas epidemias, aunado otras patologías importadas por los europeos (viruela, sarampión y “tabardillo" (tifus exantemático) ) y la hambruna por plagas y sequías, fue tal que para 1572 se estimaba que un tercio de la población indígena había sucumbido. Otras epidemias de fiebre amarilla ocurrieron en 1648-1650 y en 1699. El brote epidémico de la fiebre amarilla de 1648 fue descrito por Fray Diego López Cogolludo en su "Historia de Yucatán" escrita en 1688. La epidemia predominó en la región por un lapso de dos años y su efecto fue tan desbastador que la actividad milpera se colapsó y en 1650 hubo hambruna y las comunidades fueron despobladas al huir los mayas a las zonas selváticas o a la costa. La fiebre amarilla en Yucatán ya era endémica. Sin embargo se tuvo que afrontar cuatro brotes epidémicos más: en 1699, en 1715, en 1730 y en 1744.

(Rev Biomed 2000; 11:301-307)

Solicitud de sobretiros: M.C. Renán A. Góngora-Biachi, Centro de Investigaciones Regionales "Dr. Hideyo Noguchi”, Ave. Itzáes No 490 por 59 , C.P. 97000, Mérida, Yucatán, México. Correo electrónico: gbiachi@tunku.uady.mx Recibido el 15/Nov./2000. Aceptado para publicación el 8/Dic./2000. 


\section{RA Góngora-Biachi.}

Palabras clave: fiebre amarilla, epidemias, Yucatán, Historia de la Medicina.

\section{SUMMARY.}

The yellow fever in Yucatan before Columbus period and colonial period.

Yellow fever is a haemorrhagic fever syndrome caused by a flavivirus, the yellow fever virus, which is transmitted by the Aedes aegypti and Haemagogus mosquitoes. The Yellow fever virus has caused important epidemics in America, Africa and Europe. The Popol-Vuh, the sacred book of the mayan indians, relates how yellow among the mayans was due to their living in close proximity to monkeys and tells of a sickness called "xekik" (vomitting blood) which ocurred between 1480 and 1485. Other sacred texts such as the Chilam Balam of Chumayel, Tizimín and Kaua also described the epidemics of "xekik". Fray Diego de Landa, in his book Relación de las Cosas de Yucatán, writt in 1560, refers to the first epidemic in the region which ocurred approximately from 1483 to 1484 . There were epidemics of yellow fever in 1569 and 1571-1572 described as the "peste". The impact of these epidemics, added to other pathologies imported by the Europeans (small pox, measles and "tabardillo" (exantematic tifus)) and starvation by plagues and droughts, caused the indigenous population to be reduced by one third by 1572 . Other yellow fever ocurred in 1648-1650 and in 1699. The 1648 outbreak of the yellow fever epidemic was described by Fray Diego López Cogolludo, in his "Historia de Yucatán", written in 1688. The epidemic predominated in the region for two years and its effect was so devasting that the agricultural activity collapsed, in 1650 there was famine and the communities were abandoned as the mayans fleed to the jungle ot the coast. Yellow fever in Yucatan was then endemic. However, four more outbreaks occurred in 1699 , 1715, 1730 and in 1744 .

(Rev Biomed 2000; 11:301-307)
Key words: Yellow fever, epidemics, Yucatan, History of Medicine.

\section{INTRODUCCIÓN.}

La fiebre amarilla es un síndrome de fiebre hemorrágica ocasionada por un flavivirus, el virus de la fiebre amarilla, y que es transmitido por los mosquitos Aedes aegypti y Haemagogus (1). El virus de la fiebre amarilla ha causado epidemias importantes en el continente americano, Africa y Europa. El periodo de incubación de este virus es de 3 a 6 días, ocasiona una mortalidad de $20 \%$, no tiene preferencia por edades ni por género. Posterior al periodo de incubación la enfermedad se manifiesta por ictericia, hemorragias, vómitos negros, anuria y delirio final, ocasionado por la necrosis hepática que ocasiona esta fiebre hemorrágica (1). Desde marzo de 1923 y hasta la fecha se considera erradica de México (2).

El virus de la fiebre amarilla tiene un ciclo selvático y un ciclo urbano. En el ciclo selvático participan los monos y los mosquitos Aedes en África y los mosquitos Haemagogus en las selvas tropicales americanas. Aunque en la época precolombina ya se describían casos de fiebre amarilla en América, debe atribuirse estos casos al ciclo selvático y las epidemias ocasionadas durante el periodo de la conquista europea y la época colonial se atribuyen a la importación al nuevo mundo del A. Aegypti, vector que ha sido el causante de los brotes urbanos (3).

\section{LA FIEBRE AMARILLA EN LA ÉPOCA PRECOLOMBINA.}

El Popol-Vuh, libro sagrado de los mayas quichés, relata que la fiebre amarilla entre los mayas se debe a la constante convivencia con los monos y relata la epidemia de una enfermedad llamada xekik (vómito de sangre) ocurrida entre los años de 1480 a 1485 (3). Interesantemente y con una anticipación de más de quinientos años del descubrimiento del A. Aegypti como el vector de

\section{Revista Biomédica}


Fiebre amarilla en Yucatán.

la fiebre amarilla, el Popol-Vuh narra claramente el modo de transmisión de la enfermedad de los monos al hombre: "por medio de un mosquito creado por los dioses" (3). Otros textos sagrados como el Chilam Balam de Chumayel, Tizimín y Kaua también describen las epidemias de xekik en la siguiente forma: durante el Katun 4 Ahau (14801500) "hubo mortandad súbita, los zopilotes entraron en las casas de Ichpá (Mayapán)" (4).

Fray Diego de Landa, en su obra Relación de las Cosas de Yucatán, escrita en 1560 aproximadamente, hace mención de las epidemias referidas en los libros del Chilam Balam y menciona la posibilidad de que el mal se presentará en el futuro ya que había aparecido anteriormente en tres ocasiones (5).

Landa refiere que la primera epidemia en la región fue 22 ó 23 años después la destrucción de Mayapán y dieciséis años después de un desbastador huracán. Así, el inicio de esta epidemia de fiebre amarilla ocurrió aproximadamente en 148384. Esta epidemia es descrita por este historiador con el siguiente texto: (cuando los naturales) "queriendo comenzar a coger frutos, sobrevinieron unas calenturas pestilenciales que duraban veinticuatro horas y después de cesadas, se hinchaban (los enfermos) y reventaban llenos de gusanos... y con esta pestilencia murió mucha gente y gran parte de los frutos quedó sin recoger" (5).

\section{LAS EPIDEMIAS DURANTE LA ÉPOCA COLONIAL.}

A América los huevezuelos deAedes aegypti fueron importados por las carabelas de Cristóbal Colón. Las consecuencias de este hecho fueron los brotes de fiebre amarilla desbastadores en $\mathrm{La}$ Isabela (Santo Domingo). El cronista Oviedo describe: "En 1494 nació entre los españoles una peste y una gran corrupción... causada por la extrema humedad del país. Los hombres que sobrevivieron quedaron afligidos de enfermedades incurables, y entre los que regresaron a España (con Cristóbal Colón), los había cuya cara se había vuelto de un color amarillo azafrán No tardaron de morir de las enfermedades que había adquirido, y les daba el color del oro que habían ido a buscar a los países alejados" (3). A partir de entonces ocurrió una secuencia de epidemias de fiebre amarilla en la Cuenca del Caribe. De estos puntos y a través de las expediciones españolas se importa a México el Aedes aegypti. La expedición de Juan de Grijalva en 1518, desde Cuba hasta Tabasco y Veracruz, no reportó la presencia de la enfermedad. En 1519 Hernán Cortés establece la Villa Rica de la Vera Cruz y fue hasta 1521 cuando - en coincidencia con las nuevas inmigraciones de españoles- se hizo presente el "vómito negro" (3).

Sanfilippo refiere que en Yucatán el primer brote de fiebre amarilla producido por el Aedes aegypti ocurrió después de primera expedición de Francisco de Montejo, el Adelantado, en 1527 (3). Sin embargo el Chilam Balam describe que en el 2 Ahau (1520-1520) "hubo epidemia de viruela grande" (4) y probablemente no haya sido en realidad un brote de fiebre amarilla.

Después de la fundación de Valladolid -24 de mayo de 1543- en su sitio inicial de ChahuacHa (sitio cercano a la costa noreste de Yucatán) la villa tiene que trasladarse a su actual asentamiento por condiciones insalubres y enfermedad. En las "Relaciones Histórico-Geográficas de la Región de Valladolid" elaboradas en 1577, se describe: "en espacio de poco más de un año se le habían muerto del servicio y amigos que habían llevado a Chauac-Ha más de seiscientos indios y algunos españoles y que la tierra era enferma, pluviosa y húmeda... determinó pasar la villa y vecinos de Chahuac-Ha a este asentamiento de Valladolid", evento que aconteció en marzo de 1545(6). Se desconoce a ciencia cierta la o las enfermedades que diezmaron la población. La descripción de algunas de estas enfermedades sugieren se trata de fiebre amarilla.

Descrita como la "peste", hubo epidemias de fiebre amarilla en 1569, y 1571-1572 (7). El impacto de estas epidemias, aunado otras patologías importadas por los europeos (viruela, sarampión y

Vol. 11/No. 4/Octubre-Diciembre, 2000 


\section{RA Góngora-Biachi.}

"tabardillo" (tifus exantemático) ) y la hambruna por plagas y sequías, fue tal que para 1572 se estimaba que un tercio de la población indígena había sucumbido (7).

Quesada describe de 1590 a 1699 ocurre el tercer momento de la historia de las epidemias de Yucatán y que las epidemias aparecieron cada 18 años y dos meses en promedio (7): en 1590, 1609 y 1659 el sarampión; en 1590 y 1609 el "tabardi1lo"; en 1609 y 1659 la viruela; en 1648-1650 la fiebre amarilla. Aunque este autor describe que en 1699 ocurrió una epidemia "no identificada", es muy probable que haya sido fiebre amarilla, ya que en ese año ocurrió en Veracruz un brote de gran magnitud, asociado con la llegada de un buque inglés con un cargamento de esclavos procedentes de Africa (3).

El brote epidémico de la fiebre amarilla de 1648 ha sido uno de los mejores descritos por actores de la época. Fray Diego López Cogolludo en su "Historia de Yucatán" escrita en 1688 (8) hace una crónica muy interesante de este evento. Inicia con la narrativa de eventos premonitorios a la epidemia:

"Poco después de principiado por el mes de Marzo del año solar, por espacio de algunos días se vió el sol como eclipsado, el aire tan espeso que parecía una niebla o humo muy condensado con que se obscurecía la luz de los rayos solares. Tan general fue en toda esta tierra, que no hubo parte alguna, desde Cozumel a Tabasco, donde no estuviese de aquella mala disposición, que viéndola los indios viejos, dijeron era señal de gran mortandad de gente en esta tierra, y por nuestros pecados salió tan cierta verdad como en breve experimentó. Poco después en la ciudad de Mérida algunos días, especialmente por las tardes cuando suele ventar la virazón de la mar, venía con tan mal olor que apenas se podía tolerar, y a todas partes penetraba. No se podía entender de qué procediese, hasta que viniendo navegando un navío de España, baró en una como montaña de pejes muertos, cercanos a la costa de la mar, cuya resaca los iba echando a tierra, de donde salía el mal olor que hasta la ciudad y aún más adelante se extendía”.

El inicio de este brote epidémico al parecer ocurrió a finales de julio. Al respecto describe: "Entrando el mes de Junio comenzó el achaque de la peste en la villa de Campeche, y apretó en breves días tanto que se entendió quedara totalmente asolada. Yo ví carta de un republicano escrita a un amigo suyo, en que diciéndole la desdicha que se pasaba, y muertes de personas de todas edades que se veían cada día, concluía con decir. Si Dios no se duele de nuestra miseria y aplaca el rigor de justicia, presto se dirá aquí fue Campeche, como se dice en proverbio aquí fue Troya. Venía por horas nueva de las desdichas a la ciudad de Mérida, .... Previniéronse los caminos de Campeche recelando la comunicación del contagio; ¿pero cuando el Señor no guarda la ciudad, qué importan diligencias humanas? Con este temor de la divina justicia se pasó el mes de Julio en que a los fines comenzaron a enfermar algunas personas que morían muy brevemente: pero no se conoció ser el achaque de la peste hasta entrado el de Agosto"

La magnitud de la epidemia es elocuentemente descrita: "Con tal presteza y violencia dio en grandes y pequeños, ricos y pobres, que en menos de ocho días casi toda la ciudad a un tiempo estaba enferma, y murieron muchos de los ciudadanos de más nombre y autoridad en ella. Afligida la ciudad con tal desventura, no vista otra vez. desde que se conquistó esta tierra, entra la nación española..."

Ante tal magnitud y de acuerdo al concepto de enfermedad de la época, recurrir a la Divinidad era un camino adecuado: “...por decreto del cabildo se pidió al reverendo padre provincial diese licencia para traer la santa imagen de nuestra Señora de Izamal, a celebrarle un novenario de festividad con la solemnidad posible; y para seguridad hizo el cabildo pleito homenaje de volverla a su casa e iglesia. Habida la licencia fue nombrado por diputado para llevarla el teniente general de gobernación D. Juan de

\section{Revista Biomédica}


Fiebre amarilla en Yucatán.

Aguileta. Cuando hubo de salir por ella estaba tan enfermo del común contagio, que casi era reputado por cercano a la muerte; pero puesta su esperanza en la Virgen Santísima, y rogándole le diese salud, se hizo cargar como estaba, y que le llevasen a Izamal. Fue cosa digna de admiración, que como se iba alejando de la ciudad y acercando al sagrado depósito de la santa imagen, iba mejorando del achaque, sin remedio al parecer eficaz para ello, y cuando hubo de salir de su santo templo, pudo cargarla en hombros un buen espacio,... por la salud con que se hallaba en tan pocos días".

"La mañana que hubo de entrar en la ciudad, salieron a recibirla no sólo todos los que aun habian sanos, pero aun muchos enfermos que no podían andar se hicieron llevar al camino por donde venía, y de ellos sanaron algunos, ... Salieron de los dos cabildos eclesiásticos y secular todos los que no estaban en cama, los más de ellos descalzos los pies por el suelo en señal de humildad y penitencia. De la misma suerte iba gran número de mujeres y señoras de las más principales, todos pidiendo a Dios misericordia por los méritos y intercesión de su Santísima Madre... la llevaron primero con la procesión que iba por algunas calles principales, y los enfermos de las casas por donde pasaba, aun los que estaban para expirar, se hacían sacar a las ventanas esperando su salud con verla... Con todo aquel concurso fue llevada a la Santa Catedral, donde con gran solemnidad se cantó una misa en reverencia suya, teniéndola colocada en un altar muy adornado para ello".

La epidemia no respeto ni a las altas autoridades, ya que el gobernador Don Esteban de Azcárraga sucumbió a causa de la fiebre amarilla. Sin embargo la historia natural de la enfermedad y quizá el estado inmunológico de la población de esa época, hizo que la mortandad no fuera total. Este hecho fue atribuido a un milagro y ocasionó que se emitiera el siguiente decreto el 19 de agosto de 1648:

"Que por cuanto se ha traído a esta ciudad a la Virgen Santísima de Ytzmal, para que con sus auxilios pida y suplique a Dios nuestro Señor amaine su ira, y alce la mano a tantas muertes como ha habido en esta ciudad, pues apenas quedan personas en ella el día de hoy, y cada día van muriendo más y más; que mediante sus ruegos, y ser amparo de pecadores y afligidos, y estarlo esta ciudad tanto, parece que va cesando. Y porque el fervor de nuestros corazones no falte jamás, $y$ estar siempre como debemos estar, con tan justos y rendidos agradecimientos, tenemos propuesto elegir a la dicha Virgen Santísima de Ytzmal, por nuestra patrona y abogada contra las pestes y enfermedades, así las que al presente hay en esta ciudad, como las que adelante hubiere. $Y$ suplicamos a la Virgen Santísima nos admita, y sea nuestra protectora, patrona y abogada, ahora $y$ en adelante para siempre jamás sin fin. $Y$ en nombre de esta ciudad el cabildo, justicia y regimiento de ella que al presente somos, y adelante fuéramos, prometemos y nos obligamos de celebrar fiesta a la Virgen Santísima de Ytzmal el día de su gloriosa Asunción, que es a quince de Agosto de cada un año perpetuamente para siempre jamás. Para lo cual irán dos regidores de esta dicha ciudad al pueblo de Ytzmal..."

Sin embargo la movilización de la Virgen de Izamal propició la diseminación de la epidemia: " $A$ los más indios de Izamal que asistieron a la santa imagen en el camino y ciudad de Mérida, se les pegó el contagio de la peste en ella y a breve días como llegaron a Izamal pasaron de esta presente vida a la eterna, donde la Madre misericordia les impetraría dichosa remuneración a la fe y devoción con que la asistieron y veneraron, no teniendo el peligro tan manifiesto de la muerte que en la ciudad corrían, porque cuantos en ella entraban por aquellos días, muchos al primero, otros al segundo y últimamente todos, eran inficionados con el contagio. Algunos religiosos comarcanos del convento de Izamal que acompañaron a ida y vuelta a la santa imagen para que fuese con toda veneración, vinieron también tocados del contagio, y de ellos murieron

Vol. 11/No. 4/Octubre-Diciembre, 2000 


\section{RA Góngora-Biachi.}

los que parecían más sanos y robustos".

López Cogolludo describe la sintomatología de la siguiente manera: "Lo más común era sobrevivir a los pacientes un gravísimo e intenso dolor de cabeza y de todos los huesos del cuerpo, tan violento, que parecían descoyuntarse y que una prensa los oprimían. A poco rato daba tras el dolor calentura vehementísima que a los más ocasionaba delirios, aunque a algunos no. Seguiánse unos vómitos de sangre como podrida, y de éstos muy pocos quedaron vivos. A otros daba flujo de vientre de humor colérico, que corrompido ocasionaba disentería que llaman, sin vómitos, y otros eran provocados a ello con gran violencia sin poder hacer evacuación alguna, y muchos padecieron la calentura con el dolor de hueso sin alguno de los otros accidentes. Los remedios que se aplicaban a uno y al parecer le mejoraban la salud, aplicados a otro que parecía tener los mismos accidentes se entendió les acortaron la vida. A los más al tercer día parecía remitirse totalmente la calentura, decían que ya no sentían dolor alguno, cesaba el delirio conversando muy en juicio; pero no podían comer ni beber cosa alguna, y así duraban otro u otros días; con que hablando y diciendo que ya estaban buenos, expiraban. Fueron muchísimos los que no pasaron del tercero día, los más murieron entrados en el quinto, y muy pocos los que llegaron al senteno, si no fue los que quedaron vivos y de éstos los más fueron los de edad mayor. A los mancebos más robustos y saludables daba con más violencia y acababa la vida mas presto. Vióse una mañana uno de los más robustos mancebos de la ciudad en las gradas de la iglesia mayor sano y bueno, que dándole la enfermedad ya a las cinco de la tarde de aquel día era ya difunto. Aunque de las mujeres enfermaron muchísimas, no apretó en ellas tanto el mal como en los varones, y así respecto de ellos fueron pocas las que murieron; pero rara la que halló preñada que quedase viva".

Las medidas "terapéuticas" adoptadas también las describe: "Estando un secular con la fuerza de la calentura, se metió desnudo en un estanque de agua, y dentro de ella estuvo hasta que sintió aplacarse el calor, y después salió del agua y sanó. Un corista de nuestro convento habiéndole dado la calentura, barrió muy bien el suelo de su celda, y derramó en él una botijas de agua, y desnudándose en carnes se echó, y revolcándose en él toda la noche buscando el fresco de lo regado, amaneció sin calentura y sano. A muchos estando en el rigor de ella, se les quitó con beber agua ardiente, que es al contrario de los otros que se ha dicho, y otros sanaron con sólo sajarles una ventosas en las espaldas, y un indio sanó con sajarle una sobre el corazón, y enfermos hubo que pasaron la calentura durmiendo hasta que estuvieron sanos sin haber quien les aplicase remedio alguno. En casas de muy grandes familias apenas habían quien socorriese a los enfermos por estarlo todos a un tiempo, ni quien les pidiese los Sacramentos".

La mortandad de la epidemia la narra de la siguiente forma: "Amanecían los cementerios llenos de cuerpos muertos, unos con los vestidos que traían, otros cocidos en petates y de otras suertes, que todo causaba horror y confusión. A uno hallaron al segundo día de su enfermedad muerto en los brazos de su mujer, que quedó como embelesada y sin sentido, y así estuvo por gran espacio de tiempo. A muchas personas se les endureció el corazón que no podían llorar viendo tantas desdichas; con que era más crecida su pena. Llegó a no haber siquiera indios que en una tabla llevasen a las iglesias cuerpos de personas muy principales".

Aunque al inicio la epidemia se presentó principalmente en Campeche y Mérida, en septiembre ya había afectado a la villa de Valladolid al poco tiempo se había extendido a la mayoría de las poblaciones de la Península de Yucatán. Por la descripción de López Cogolludo puede deducirse que tuvo una dinámica de poblaciones urbanas a poblaciones rurales.

La epidemia predominó en la región por un lapso de dos años y su efecto fue tan desbastador la actividad milpera se colapsó que en 1650 hubo

\section{Revista Biomédica}


hambruna y las comunidades fueron despobladas al huir los mayas a las zonas selváticas o a la costa, debido a un decreto que del gobernador de García de Valdés Osorio que pretendía requisar los granos existentes las comunidades mayas (7).

La fiebre amarilla en Yucatán ya era endémica. Sin embargo tuvo que afrontar cuatro brotes epidémicos más: en 1699, en 1715, en 1730 y en 1744 (3). Y así la fiebre amarilla persistiría hasta el fin de a época colonial. El Yucatán del siglo XIX tampoco se libraría de esta enfermedad endémica.

\section{REFERENCIAS.}

1.- Peters CJ. Infections caused by arthropod- and rodent -borne viruses. En Fauci AS, Braunwald E, Isselbacher KJ, Wilson JD, Martin JB, Kasper DL, Hauser SL, Longo DL, eds. Harison's Principles of Internal Medicine. $14^{\text {th }}$ edition. New York: McGraw-Hill; 1998. p. 1132-46.

2.- Ortiz M. Fiebre Amarilla. En: Sepúlveda-Amor J, ed., Devenir de la salud pública en México durante el siglo XX. México: Instituto Nacional de Salud Pública; 2000. p. 55-71.

3.- Sanfilippo J. El espectacular y terrible "vómito negro". Médico Moderno 1987; 26(2):66-85.

4.- Barrera-Vásquez A, Rendón S. El libro de los libros de Chilam Balam. México: Fondo de la Cultura Económica;1948. p. 21-43.

5.- De Landa D. Relación de las Cosas de Yucatán. México: Editorial Porrúa; 1978. p. 19-20.

6.- Góngora-Biachi RA. Las Relaciones Histórico-Geográficas de la región de Valladolid, Yucatán. En Góngora-Biachi RA, Ramírez-Carrillo LA, eds. Valladolid: una ciudad, una región y una historia. Mérida:Universidad Autónoma de Yucatán; 1993. p. 85-124.

7.- Quesada S. Epidemias, plagas y hambres en Yucatán, México (1520-1700). Rev Biomed 1995; 6:238-42.

8.- López Cogolludo D. Historia de Yucatán. 5a . Ed. Campeche: H. Ayuntamiento de Campeche; 1996. p. 368-93. 